\title{
Hearing Status of the Traffic Police with or without Use of Sound Protector in Dhaka Metropolitan City
}

\author{
Ahmed Sharif ${ }^{1}$, Rashida Akter Khanam ${ }^{2}$, Mohammad Mashudur Rahman ${ }^{3}$, \\ Sheikh Hasanur Rahman ${ }^{4}$, Md. Kamaruzzaman ${ }^{5}$, Ashfaq Ahmad \\ ${ }^{1}$ Assistant Professor, Department of ENT, Mugda Medical College, Dhaka, Bangladesh; ${ }^{2}$ Assistant Professor, Department of \\ Microbiology, Shaheed Suhrawardy Medical College, Dhaka, Bangladesh; ${ }^{3}$ Assistant Professor, Department of Neurology, \\ Sheikh Sayera Khatun Medical College, Gopalgonj, Bangladesh; ${ }^{4}$ Associate Professor, Department of ENT and Head-Neck, \\ Bangabandhu Sheikh Mujib Medical University, Dhaka, Bangladesh; ${ }^{5}$ Associate Professor, Department of ENT, Khulna \\ Medical College, Khulna, Bangladesh; ${ }^{6}$ Senior Consultant (ENT), 250 bed General Hospital, Chittagong, Bangladesh
}

[Reviewed: 30 August 2016; Accepted on: 1 November 2016; Published on: 1 January 2017]

\section{Abstract}

Background: Sound protector is an essential tool to protect hearing. Objective: The purpose of the present study was to see the hearing status of traffic police with or without sound protector. Methodology: The cross-sectional study was conducted in the Department of Otolaryngology and Head Neck Surgery at Bangabandhu Sheikh Mujib Medical University, Dhaka from January 2003 to June 2004 for a period of one and half year. Traffic police who were working in the Dhaka metropolitan city at any age were included as study population. Hearing status was measured to all subjects. The traffic police at any age working in the Dhaka metropolitan city with the duration of service more than 5 years were included as study population. Otoscopic examination, tuning fork test and pure tone audiometry were performed by clinical audiometer (AC 33) with two channels, with TDH39 earphones among the entire study subject. Result: A total number of 100 traffic polices working in Dhaka metropolitan city were examined. Highest (56\%) number of the respondents was in between 30 to 40 years of age group. The mean age with SD was $36.15 \pm 5.5$. In this study $53.0 \%$ respondents found to have exposure of 6 to 10 years and $16.0 \%$ found to have exposure between 16 to 20 years. It was found that 26 traffic police used ear protector occasionally. Among them 7(26.9\%) subjects had different degree of hearing loss. Nonusers had higher rate $(23 \%)$ of hearing loss $(\mathrm{p}=0.685)$. Conclusion: In conclusion use of sound protector by traffic police is not significantly related with the hearing loss though this is clinically significant. [Journal of Current and Advance Medical Research 2017;4(1):13-16]

Keywords: Hearing status; traffic police; sound protector

Correspondence: Dr. Ahmed Sharif, Assistant Professor, Department of ENT, Mugda Medical College, Dhaka, Bangladesh; Email: entsharif@ gmail.com; Cell no.: +8801711114358

Cite this article as: Sharif A, Khanam RA, Rahman MM, Rahman SH, Kamaruzzaman M, Ahmad A. Hearing Status of the Traffic Police with or without Use of Sound Protector in Dhaka Metropolitan City. Journal of Current and Advance Medical Research 2017;4(1):13-16

Conflict of Interest: All the authors have declared that there was no conflict of interest.

Funding: This research project was not funded by any group or any institute on.

Contributions to authors: Sharif A, Khanam RA \& Rahman MM have contributed in protocol preparation up to surgical procedures as well as the report writing; furthermore, Rahman SH, Kamaruzzaman M \& Ahmad A have written the manuscript and have revised the manuscript.

Copyright: (2017 Sharif et al. Published by Journal of Current and Advance Medical Research. This article is published under the Creative Commons CC BY-NC License (https://creativecommons.org/licenses/by-nc/4.0/). This license permits use, distribution and reproduction in any medium, provided the original work is properly cited, and is not used for commercial purposes. 


\section{Introduction}

Excessive noise exposure is the major avoidable cause of permanent hearing impairment worldwide $^{1}$. In a developed country, it is at least partially the cause in more than one third of those with hearing impairment ${ }^{2}$ and, in many countries, is biggest compensatable occupational hazard ${ }^{3}$. Urban traffic noise pollution is increasing risk factor for hearing impairment ${ }^{4}$. As populations live longer and industrialization and urbanization spreads, noise induced hearing loss (NIHL) will add substantially to the global burden of disability, and hence has a high public health priority ${ }^{5}$.

In the elderly, NIHL may add to the hearing loss of presbyacusis to produce a hearing handicap sooner and worse than would occur from age alone. In Thailand a recent study for the National committee on Noise Pollution control of Thailand measured noise exposure and hearing impairment in various occupational groups and found 21.1 to $37.7 \%$ with noise induced hearing $\operatorname{loss}^{6}$. In Europe, the population exposed to levels above $65 \mathrm{~dB}$ increased from $15 \%$ in 1980 s to $26 \%$ in the early 1990 s $^{7}$. For comparison, speech can be understood fairly well with the background noise level upto $55 \mathrm{~dB}$. Environmental noise affect health and well being physically, mentally and socially ${ }^{8}$.

In developing country like Bangladesh, occupational noise and urban environmental noise especially traffic noise are the increasing risk factors for hearing impairment. The traffic police who are regularly exposed to this traffic noise in Dhaka Metropolitan city are very much susceptible to noise induced hearing loss.

Traffic noise is probably an alarming hazard, but the scale of problem and its effects needs further systemic high quality research on long term damage. Therefore this present study was undertaken to see the hearing status of traffic police with or without sound protector in Dhaka metropolitan city.

\section{Methodology}

This study was designed as cross-sectional study. This present study was conducted in the Department of Otolaryngology and Head Neck Surgery at Bangabandhu Sheikh Mujib Medical University from the duration of January 2003 to June 2004 for a period of one and half year. The traffic police at any age working in the Dhaka metropolitan city with the duration of service more than 5 years were included as study population. Traffic police presented with systemic disease like hypertension, diabetes mellitus, collagen disease, past history of viral disease, drug therapy which may cause SNHL, duration of service less than 5 years and previous history of otitis media and Known causes of conductive or sensorineural hearing loss were excluded from this study.

Data was collected by face to face in pretested structured questionnaire. Informed verbal consent taken from all study person. Otoscopic examination, tuning fork test and pure tone audiometry were performed by clinical audiometer (AC 33) with two channels, with TDH39 earphones among the entire study subject. Calibration was air conduction ISO 389-1992. Bone conduction was ISO 7566 or ANSI S3.43-1992. Pure tone Audiometry was performed in the early morning by an experienced audiologist. Tympanometry was done by automatic impedance audiometer AT 22. Noise level was measured at 18 different places of Dhaka city. Noise level measured for consecutive 6 days (SaturdayThursday) in different hours and levels were observed where then averaged noise level was taken. Type-2 noise level meter [Type-2 noise level meter: Standard conformance to IEC (International Electrotechnical commission) publication 123 for sound level meters, JIS (Japanese Industrial Standards) C1502 for sound level meters] was used. Statistical analysis was performed by SPSS. All collected data were checked and verified thoroughly to reduce the inconsistency. The numerical data obtained from this study were complied and analyzed using standard statistical method. $P$ value of $<0.05$ was considered to be statistically significant.

\section{Results}

A total number of 100 traffic polices working in Dhaka metropolitan city were examined. Highest (56\%) number of the respondents was in between 30 to 40 years of age group and $23.0 \%$ belonged to age group 41 to 45 years and $21 \%$ were in 20 to 30 years age group. The mean age with standard deviation (SD) was $36.15 \pm 5.5$ (Table 1).

Table 1: Age Distribution of the Study Subjects $(n=100)$

\begin{tabular}{|l|c|c|}
\hline Age Group & Frequency & Percentage \\
\hline 21 to 30 Years & 21 & 21.0 \\
\hline 31 to 40 Years & 56 & 56.0 \\
\hline 41 to 45 Years & 23 & 23.0 \\
\hline Total & $\mathbf{1 0 0}$ & $\mathbf{1 0 0 . 0}$ \\
\hline *Mean $\pm S D=36.15( \pm 5.5)$ years & \\
\hline
\end{tabular}

In this study $53.0 \%$ respondents found to have exposure of 6 to 10 years and $16.0 \%$ found to have exposure between 16 to 20 years (Table 2). 
Table 2: Duration of Noise Exposure of the Respondents $(n=100)$

\begin{tabular}{|l|c|c|}
\hline $\begin{array}{l}\text { Duration of } \\
\text { exposure }\end{array}$ & Frequency & Percentage \\
\hline 6 to 10 Years & 53 & 53.0 \\
\hline 11 to 15 Years & 31 & 31.0 \\
\hline 16 to 20 Years & 16 & 16.0 \\
\hline Total & $\mathbf{1 0 0}$ & $\mathbf{1 0 0 . 0}$ \\
\hline *Mean \pm SD $=11.2 \pm 3.6$ years & &
\end{tabular}

It was found that 26 traffic police used ear protector occasionally. Among them 7(26.9\%) subjects had different degree of hearing loss. Nonusers had higher rate $(23 \%)$ of hearing loss $(\mathrm{p}=0.685)$ (Table $3)$.

\section{Table 3: Hearing Status of the Users of Sound Protector $(n=100)$}

\begin{tabular}{|c|c|c|c|}
\hline Ear & Hear & status & Total \\
\hline $\begin{array}{l}\text { Protecto } \\
\mathbf{r}\end{array}$ & Normal & Impaired & \\
\hline Yes & $19(73.1 \%)$ & $7(26.9 \%)$ & $26(100.0 \%)$ \\
\hline No & $57(77.0 \%)$ & $17(23.0 \%)$ & $74(100.0 \%)$ \\
\hline Total & $76(76.0 \%)$ & $24(24.0 \%)$ & $\mathbf{1 0 0}(100.0 \%)$ \\
\hline
\end{tabular}

* Chi-square test was done to see the level of significance; $\mathrm{P}$ value $=0.685$

\section{Discussion}

In Bangladesh noise pollution is a health hazard. Increasing ambient noise level in public places from various sources like industrial activity, construction activity, vehicular horn, generator set, loudspeaker, music system, other mechanical device. All the city dwellers are exposed to these noise pollution, but the traffic police of Dhaka metropolitan city are continuously exposed to traffic noise arising from diesel engine vehicle and their hydraulic horn and also from other sources. In Bangladesh there was no study of noise induced hearing loss among the traffic police who are exposed to noise exposure during their 8 hour duty in different places of Dhaka metropolitan city.

In this cross sectional study, 100 traffic police were included for otological and audiological evaluation. Age and duration of exposure was considered. Age of the respondent traffic police was divided into three groups. 56\% were in the group between 31-40 years, $23 \%$ were in $41-45$ years and rest belongs to 20-30 years group. Mean age was 36.15 year with SD ( \pm 5.5$)$. Only $16 \%$ had duration of exposure between 16-20 years and 31\% had duration of exposure between 11-15 years and rest had duration of exposure between 6-10 years. Mean exposure duration were 11.2 year with SD $( \pm 3.6)$. This study showed, however, that majority of noise exposed traffic police did not complain of any hearing difficulty despite of the presence of hearing impairment as shown by their audiogram. Only $5 / 24$ $(20.8 \%)$ of the traffic police with hearing impairment complained of having difficulty in hearing, while $79.2 \%$ alleged to have normal hearing. Good hearing threshold at essential speech frequencies $(500$ to $2000 \mathrm{~Hz}$ ) is important for speech discrimination?

A similar study ${ }^{10}$ reported that $16.9 \%$ of the workers with hearing impairment complained of having difficulty in hearing in a factory, while, $83.1 \%$ alleged to have normal hearing which is consistent with the present study result. Noise induced hearing loss report in Taiwan was found that $19.9 \%$ had mild NIHL and $14.1 \%$ had sever NIHL ${ }^{11}$. Among different frequencies, participants hearing threshold at 4 and $6 \mathrm{KHz}$ were all higher in both ears, which is compatible those found in typical cases of noise induced hearing loss. It has been estimated that about $17 \%$ of production worker have at least mild hearing loss resulting from occupational noise exposure; $11 \%$ have moderate and $5 \%$ have moderate to severe hearing loss. No significant difference was found between right and left ear of the respondent traffic police. This finding indicates that adverse noise effect is generally bilateral and symmetrical which is consistent with other study ${ }^{12}$.

In this study the magnitude of higher hearing threshold change was found in frequencies at 4 and $6 \mathrm{KHz}$. In this study only $26.0 \%$ told that they sometime used cotton plug as hearing protector device. Among the ear protector users 7/24 (29.5\%) of them found to have hearing loss. 17/24 (70.8\%) of hearing impaired did not use any hearing protector. The common reason of not using hearing protector was lack of knowledge about noise induced hearing loss. Only few told that this device is not comfortable and causes difficulty in understanding conversation; furthermore it is used for working in noisy environment. The correlation between awareness of hazards of noise to hearing and attitude towards hearing protection device shown in this study is worth nothing. This is well supported by the findings of another study ${ }^{13}$.

In another study Ahmed ${ }^{14}$ has showed that the rate of full use hearing protection user, when the noise level was more the $85 \mathrm{dBA}$, were only $9.0 \%$ and sometime use was only slightly higher at $30.0 \%$. This study further confirms the well-documented conclusion that all time use of hearing protection devices protect the hearing, and that wearing hearing protection devices only sometime is in practice, similar to non-use ${ }^{14}$. An epidemiological study was carried out in Polland ${ }^{15}$. It was found that 
occupational noise induced hearing loss was most frequent among all occupational diseases, and its incidence rate exceeds 16 new cases annually per 100000 employees. In another study the authors were concluded that exposed to $98 \mathrm{dBA}$ accelerates the evaluation of hearing loss, this trend being more pronounced in male ${ }^{16}$.

Limitations are quite common in any study short or long, retrospective or prospective and fewer or larger sample. Still then overcoming limitations is really essential to conduct any study. Considering significant outcome of the study, this study has tried to overcome the limitations as far as possible. Beyond the scope few limitations were faced during doing the study. The exact intensity of the noise of the affected traffic police cannot found because they work in different places of Dhaka metropolitan city in different time of their duty. The magnitude of sound level is different in different places of Dhaka city.

\section{Conclusion}

In conclusion use of sound protector by traffic police is not significantly related with the hearing loss; however, the relationship is clinically significant. The duration of noise exposure is more than 10 years in majority of the study population. The measurement of the status of hearing should be carried as a routine procedure or as a emergency basis when the traffic police complains of either deafness or ringing in the ears.

\section{References}

1. Nandi SS, Dhatrak SV. Occupational noise-induced hearing loss in India. Indian journal of occupational and environmental medicine. 2008;12(2):53

2. Ahmed HO, Dennis JH, Badran O, Ismail M, Ballal SG, Ashoor A, Jerwood D. Occupational noise exposure and hearing loss of workers in two plants in eastern Saudi Arabia. Department of Family and Community Medicine, College of Medicine, King Faisal University, Dammam, Saudi Arabia. Ann Occup Hyg 2001;45:371-80

3. Lesage FX, Jovenin N, Deschamps F, Vincent S. Noiseinduced hearing loss in French police officers. Occupational Medicine. 2009;59(7):483-6
4. Shrestha I, Shrestha BL, Pokharel M, Amatya RC, Karki DR. Prevalance of Noise Induced Hearing Loss among Traffic Police Personnel of Kathmandu Metropolitan City. Kathmandu University Medical Journal. 2012;9(4):274-8

5. Abel SM. Hearing loss in military aviation and other trades: Investigation of prevalence and risk factors. Aviation, space, and environmental medicine. 2005;76(12):1128-35

6. Picard M, Girard SA, Courteau M, Leroux T, Larocque R, Turcotte F, Lavoie M, Simard M. Could driving safety be compromised by noise exposure at work and noiseinduced hearing loss?. Traffic injury prevention. 2008;9(5):489-99

7. Austin DF. Anatomy of Ear. In: Ballenger JJ, Snow JB, eds. Otolaryngology-Head and Neck Surgery, 15th edn. Philadelphia: Williams and Wilkins. 1996. 838-57

8. Bauer P, Körpert K, Neuberger M, Raber A, Schwetz F. Risk factors for hearing loss at different frequencies in a population of 47388 noise-exposed workers. The Journal of the Acoustical Society of America 1991;90(6):3086-98

9. Bratton WW. The New York City Police Department's civil enforcement of quality-of-life crimes. JL \& Pol'y. 1994;3:447

10. Giguère C. Hearing loss prevention and auditory awareness in the noisy workplace. In Proceeding 20th International Congress on Sound and Vibration $2013 \mathrm{Jul}$ (pp. 7-11)

11. Feder K, Michaud D, McNamee J, Fitzpatrick E, Davies $\mathrm{H}$, Leroux T. Prevalence of Hazardous Occupational Noise Exposure, Hearing Loss, and Hearing Protection Usage Among a Representative Sample of Working Canadians. Journal of Occupational and Environmental Medicine. 2017 Jan 1;59(1):92-113.

12. Lichtenberg I. Police discretion and traffic enforcement: A government of men. Clev St L Rev 2002;50:425.

13. Abel SM. Risk factors for the development of noiseinduced hearing loss in Canadian Forces personnel. External Client Report, DRDC Toronto ECR. 2004 Sep; 116 .

14. Sharif A, Taous A, Siddique BH, Dutta PG. Prevalence of noise induced hearing loss among traffic police in Dhaka Metropolitan City. Mymensingh Med J 2009;18(1 Suppl):S24-28

15. Reid A, Dick F, Semple S. Dog noise as a risk factor for hearing loss among police dog handlers. Occupational Medicine. 2004 Dec 1;54(8):535-9.

16. McShane DP, Hyde ML, Alberti PW. Tinnitus prevalence in industrial hearing loss compensation claimants. Clinical otolaryngology 1988;13:323-30 